\title{
Pain in knee osteoarthritis is associated with variation in the neurokinin 1/substance $P$ receptor (TACR1) gene
}

DOI:

10.1002/ejp. 1027

\section{Document Version}

Final published version

Link to publication record in Manchester Research Explorer

\section{Citation for published version (APA):}

Warner, S. C., Walsh, D. A., Laslett, L. L., Maciewicz, R. A., Soni, A., Hart, D. J., Zhang, W., Muir, K., Dennison, E. M., Leaverton, P. E., Rampersaud, E., Cooper, C., Spector, T. D., Cicuttini, F. M., Arden, N. K., Jones, G., Doherty, M., \& Valdes, A. M. (2017). Pain in knee osteoarthritis is associated with variation in the neurokinin 1/substance $\mathrm{P}$ receptor (TACR1) gene. European journal of pain (London, England).

https://doi.org/10.1002/ejp.1027

\section{Published in:}

European journal of pain (London, England)

\section{Citing this paper}

Please note that where the full-text provided on Manchester Research Explorer is the Author Accepted Manuscript or Proof version this may differ from the final Published version. If citing, it is advised that you check and use the publisher's definitive version.

\section{General rights}

Copyright and moral rights for the publications made accessible in the Research Explorer are retained by the authors and/or other copyright owners and it is a condition of accessing publications that users recognise and abide by the legal requirements associated with these rights.

\section{Takedown policy}

If you believe that this document breaches copyright please refer to the University of Manchester's Takedown Procedures [http://man.ac.uk/04Y6Bo] or contact uml.scholarlycommunications@manchester.ac.uk providing relevant details, so we can investigate your claim.

\section{OPEN ACCESS}




\title{
Pain in knee osteoarthritis is associated with variation in the neurokinin 1/substance $P$ receptor (TACR1) gene
}

\author{
S.C. Warner ${ }^{1,2}$, D.A. Walsh ${ }^{1,3}$, L.L. Laslett ${ }^{4}$, R.A. Maciewicz ${ }^{5}$, A. Soni ${ }^{6}$, D.J. Hart ${ }^{7}$, W. Zhang ${ }^{1,3}$, K.R. Muir ${ }^{8}$, \\ E.M. Dennison ${ }^{9}$, P. Leaverton ${ }^{10}$, E. Rampersaud ${ }^{11}$, C. Cooper ${ }^{6,9}$, T.D. Spector ${ }^{7}$, F.M. Cicuttini ${ }^{12}$, \\ N.K. Arden ${ }^{6,9}$, G. Jones ${ }^{4}$, M. Doherty ${ }^{1,3}$, A.M. Valdes ${ }^{1,3}$ \\ 1 Academic Rheumatology, University of Nottingham, UK \\ 2 Department of Cardiovascular Sciences, Leicester Cardiovascular Biomedical Research Unit, University of Leicester and National Institute for \\ Health Research, UK \\ 3 Arthritis Research UK Pain Centre, School of Medicine, University of Nottingham, UK \\ 4 Menzies Institute for Medical Research, University of Tasmania, Hobart, Australia \\ 5 Respiratory, Inflammation and Autoimmunity Innovative Medicines, AstraZeneca, Cambridge, UK \\ 6 NIHR Musculoskeletal Biomedical Research Unit, University of Oxford, UK \\ 7 Department of Twin Research, St Thomas' Hospital, King's College London, UK \\ 8 Institute of Population Health, University of Manchester, UK \\ 9 MRC Lifecourse Epidemiology Unit, Southampton General Hospital, University of Southampton, UK \\ 10 The Arthritis Research Institute of America, Clearwater, USA \\ 11 University of Miami Miller School of Medicine, USA \\ 12 Department of Epidemiology and Preventive Medicine, Monash University Medical School, Melbourne, Australia
}

\section{Correspondence}

Sophie C. Warner

E-mail: scw27@le.ac.uk

\section{Funding sources}

SCW is funded by a PhD studentship from the University of Nottingham. AMV was supported by a grant to the Arthritis Research UK Pain Centre grant 108239 LLL is supported by a National Health and Medical Research Council Early Career Fellowship (Clinical Research Fellowship) (GNT1070586). The Hertfordshire Cohort Study was supported by the Medical Research Council (MRC) of Great Britain; Arthritis Research UK; and the International Osteoporosis Foundation. The work was also supported by the NIHR Nutrition BRC, University of Southampton and the NIHR Musculoskeletal BRU, University of Oxford.

Conflicts of interest

None declared.

\section{Accepted for publication}

21 January 2017

doi:10.1002/ejp.1027

\begin{abstract}
Background: Substance P (SP) is a pain- and inflammation-related neuropeptide which preferentially binds to the neurokinin receptor 1 $\left(\mathrm{NK}_{1}\right)$. SP and $\mathrm{NK}_{1}$ receptors have been implicated in joint pain, inflammation and damage in animal models and human studies of osteoarthritis (OA). The aim of this study was to test if genetic variation at the neurokinin 1 receptor gene (TACR1) is associated with pain in individuals with radiographic knee OA.
\end{abstract}

Methods: Participants from the Genetics of OA and Lifestyle study were used for the discovery group $(n=1615)$. Genotype data for six SNPs selected to cover most variation in the TACRI gene were used to test for an association with symptomatic OA. Replication analysis was performed using data from the Chingford 1000 Women Study, Hertfordshire Cohort Study, Tasmanian Older Adult Cohort Study and the Clearwater OA Study. In total, $n=1715$ symptomatic $\mathrm{OA}$ and $n=735$ asymptomatic OA individuals were analysed.

Results: Out of six SNPs tested in the TACR1 gene, one (rsl1688000) showed a nominally significant association with a decreased risk of symptomatic OA in the discovery cohort. This was then replicated in four additional cohorts. After adjusting for age, gender, body mass index and radiographic severity, the $G$ (minor) allele at rsll688000 was associated with a decreased risk of symptomatic OA compared to asymptomatic $\mathrm{OA}$ cases $\left(p=9.90 \times 10^{-4}, \quad\right.$ OR $=0.79 \quad 95 \% \quad 0.68-0.90$ after meta-analysis).

Conclusions: This study supports a contribution from the TACRI gene in human OA pain, supporting further investigation of this gene's function in OA. 
Significance: This study contributes to the knowledge of the genetics of painful osteoarthritis, a condition which affects millions of individuals worldwide. Specifically, a contribution from the TACRl gene to modulating pain sensitivity in osteoarthritis is suggested.

\section{Introduction}

Osteoarthritis (OA) is a major source of pain and disability, and yet many people with radiographic OA might be asymptomatic (Hunter et al., 2013). Radiographic change is weakly associated with OA pain, indicating that OA pain is modulated by other mechanisms in addition to structural damage (Hunter et al., 2013). OA pain variation between individuals might in part be due to genetic factors which influence pain sensitivity.

Substance P (SP) is a pain- and inflammationrelated neuropeptide found in the peripheral and central nervous system as part of the $\mathrm{NK}_{1}$ pain pathway. SP has been implicated in pain and swelling in OA (Marshall et al., 1990; Lindh et al., 1997). In one study, levels of SP were higher in the cerebrospinal fluid of individuals with painful OA versus control participants (Lindh et al., 1997). SP has also been reported to be elevated in synovial fluid from individuals with knee OA compared to controls (Marshall et al., 1990).

Substance P preferentially binds to the neurokinin receptor $1\left(\mathrm{NK}_{1}\right.$, also known as the tachykinin 1 receptor, TACR 1 ). This receptor mediates the effects of SP.

Research has linked the upregulation of SP and $\mathrm{NK}_{1}$ receptors (in response to catabolic growth factors) to accelerated matrix degradation in knee chondrocytes (Im et al., 2008).

$\mathrm{NK}_{1}$ receptors have also been implicated in depression (Hallberg, 2015). This is relevant to the study of pain and OA as low mood is associated with augmented central pain processing and worse selfreported pain in knee OA (de Luca et al., 2016).

These findings support a possible contribution of $\mathrm{NK}_{1}$ and SP to OA pain.

Currently, research on genetic variants in the TACRI gene has focused mostly on psychological and psychiatric conditions such as bipolar disorder, attention deficit hyperactivity disorder (ADHD) and alcohol dependence (Sharp et al. 2014, Yan et al. 2009, Blaine et al. 2013). For example, the variant rs3771829 has been linked to both bipolar disorder and ADHD (Sharp et al. 2014, Yan et al. 2009) and the variant rs11688000 has been associated with alcohol dependence (Blaine et al. 2013). Variants rs3771863, rs3755459 and rs1106855 on the other hand, predict an activation response in response to alcohol cues (Blaine et al. 2013).

The role variation in the TACRI gene in pain has been less studied. Klepstad et al. (2011) failed to find any association between 10 variants in the TACRI gene and the mean opioid dose used for cancer pain patients. On the other hand, in an exploratory study Storm et al. (2013) reported that variants in TACRI were nominally associated with skin conductivity and clinical stress score responses to tetanic nociceptive stimuli under general anaesthesia suggesting that genetic variation in this receptor (along with beta arrestin, dopamine receptor D3 and P-glycoprotein) could be implicated in genetic predisposition to pain sensitivity although this study did not adjust for multiple testing.

Based on the role of SP in OA pain and the likely involvement of genetic variation in nociceptive responses, we hypothesized that genetic variations in TACRI might contribute to pain sensitivity in knee OA. Our goal was to investigate variants in the SP receptor (TACRI) gene to test for an association with symptomatic OA, but the variants in this gene studied to date have not been reported to have a clear functional role (e.g. binding affinity or expression levels). We therefore investigated six variants that cover most of the variation in this gene and tested them for correlation with pain in individuals with radiographic OA damage. We then proceeded to validate these findings in independent cohorts of knee OA patients.

\section{Materials and methods}

\subsection{Study participants}

The relevant research ethics committee or institutional review boards approved the study protocols for each of the five cohorts used in this study. For all participants, radiographic knee OA was defined as a Kellgren-Lawrence (K/L) grade $\geq 2$ at the tibiofemoral compartment at one or both knees and controls were individuals with $\mathrm{K} / \mathrm{L}<2$. The GOAL study was used as a discovery cohort and data derived from the Hertfordshire Cohort Study (HCS), the Chingford 1000 Women study, the Tasmanian Older 
Adult Cohort (TASOAC) and the Clearwater Osteoarthritis Study (COS) were used for replication analysis. These cohorts have been described in detail previously (Valdes et al., 2011) and are summarized briefly below and in Table 1.

\subsubsection{Genetics of OA and lifestyle (GOAL) study (Discovery)}

Participants with clinically severe knee OA, who were recruited from hospital orthopaedic surgery lists, were recruited for the cases in the Nottinghamshire-based GOAL study (previously described by Valdes et al., 2011). These individuals were used for the discovery group in this analysis, excluding individuals with hip OA but no knee OA. Individuals with current knee pain for 15 or more days of a month during the past year were classified as symptomatic knee OA cases. Individuals without such pain were classified as asymptomatic knee OA cases. Control participants were recruited from a urology clinic at the same hospital and had no knee symptoms. If radiographic knee OA was found in these individuals, they were classified as asymptomatic OA. X-rays were scored by a single observer using K/L grades for each knee joint. Approval was obtained from the research ethics committees of Nottingham City Hospital and North Nottinghamshire. Information about depression as a comorbidity was obtained via the use of a questionnaire, which asked individuals if they had ever been diagnosed with this condition.

\subsubsection{Hertfordshire cohort study (HCS)}

This is a large, population-based study and has been previously described (Aihie Sayer et al. 2004). Ethical approval was obtained from East and North Hertfordshire ethical committees. Men and women were recruited and attended a clinic for further investigation; a subgroup underwent knee X-rays. Individuals with $K / L \geq 2$ at the tibiofemoral compartment of one or both knees were included and were classified as having painful OA if they reported pain on most days in the last month.

\subsubsection{Chingford 1000 women study}

This study is a prospective population-based longitudinal cohort, including women derived from the register of a large general practice in North London. The study design and rationale are described by Hart $\delta$ Spector (1993). The Guy's St. Thomas' Trust and the local ethics committee approved the study and written consent was obtained from each woman (Outer North East London Research Ethics Committee (formerly Barking $\&$ Havering and Waltham Forest RECs), LREC (R\&WF) 96). Radiographic knee OA was classified using standard X-rays of weight-bearing

Table 1 Descriptive statistics for symptomatic osteoarthritis (OA) and asymptomatic OA participants in each study group.

\begin{tabular}{|c|c|c|c|c|c|}
\hline Cohort name & $\begin{array}{l}\text { Genetics of } \\
\text { osteoarthritis } \\
\text { and lifestyle }\end{array}$ & $\begin{array}{l}\text { Hertfordshire } \\
\text { cohort study }\end{array}$ & Chingford study & $\begin{array}{l}\text { Tasmanian older } \\
\text { adult cohort }\end{array}$ & $\begin{array}{l}\text { Clearwater } \\
\text { osteoarthritis } \\
\text { study }\end{array}$ \\
\hline Cohort acronym & GOAL & $\mathrm{HCS}$ & Chingford & TASOAC & $\cos$ \\
\hline Reference for cohort details & $\begin{array}{l}\text { Valdes et al. } \\
\text { (2011) }\end{array}$ & $\begin{array}{l}\text { Aihie Sayer } \\
\text { et al. (2004) }\end{array}$ & $\begin{array}{l}\text { Hart and } \\
\text { Spector (1993) }\end{array}$ & $\begin{array}{l}\text { Saunders } \\
\text { et al. (2012) }\end{array}$ & $\begin{array}{l}\text { Wilder et al. } \\
\text { (2002) }\end{array}$ \\
\hline Country of origin & UK & UK & UK & Australia & USA \\
\hline rs11688000 HWE H-value $^{\mathrm{a}}$ & 0.49 & 0.94 & 0.22 & 0.72 & 0.23 \\
\hline Symptomatic knee $\mathrm{OA}^{\mathrm{a}}$ & $n=1232$ & $n=86$ & $n=71$ & $n=94$ & $n=83$ \\
\hline Mean age (SD) & $68.4(7.2)$ & $65.3(2.8)$ & $55.7(5.8)$ & $65.0(7.2)$ & $64.8(7.8)$ \\
\hline$\%$ Female & $47.89 \%$ & $45.30 \%$ & $100 \%$ & $41.50 \%$ & $67.50 \%$ \\
\hline Mean BMI kgm ${ }^{-2}$ (SD) & $31.2(5.4)$ & $29.7(5.4)$ & $26.7(3.4)$ & $31.3(6.3)$ & $28.7(5.0)$ \\
\hline$\% \mathrm{~K} / \mathrm{L} \geq 3$ & $95.62 \%$ & $39.53 \%$ & $43.66 \%$ & $42.55 \%$ & $38.55 \%$ \\
\hline $\begin{array}{l}\text { TACR1 rs11688000 G } \\
\text { allele frequency }\end{array}$ & 0.361 & 0.337 & 0.324 & 0.298 & 0.337 \\
\hline Asymptomatic knee $\mathrm{OA}^{\mathrm{a}}$ & $n=383$ & $n=44$ & $n=220$ & $n=145$ & $n=92$ \\
\hline Mean age (SD) & $69.0(6.8)$ & $65.2(2.4)$ & $55.7(5.9)$ & $65.7(7.6)$ & $63.8(9.4)$ \\
\hline$\%$ Female & $43.90 \%$ & $31.80 \%$ & $100 \%$ & $56.55 \%$ & $60.90 \%$ \\
\hline Mean BMI kgm ${ }^{-2}$ (SD) & $28.9(4.9)$ & $28.4(4.0)$ & $26.3(4.4)$ & $28.1(4.3)$ & $26.4(5.0)$ \\
\hline$\% \mathrm{~K} / \mathrm{L} \geq 3$ & $67.40 \%$ & $15.90 \%$ & $28.18 \%$ & $24.83 \%$ & $20.65 \%$ \\
\hline $\begin{array}{l}\text { TACR1 rs11688000 G } \\
\text { allele frequency }\end{array}$ & 0.401 & 0.398 & 0.388 & 0.372 & 0.413 \\
\hline
\end{tabular}

${ }^{a}$ Hardy-Weinberg equilibrium $p$-value. 
knees (anteroposterior view only) and was defined as $\mathrm{K} / \mathrm{L} \geq 2$ at either knee. Symptomatic knee OA was defined as pain in the knee most days of a month over the past year. The pain data used here were assessed at the time of the 10-year X-ray and followup. Controls were classified based on the absence of radiographic knee OA regardless of pain status.

\subsubsection{Tasmanian older adult cohort (TASOAC) study}

This study is an ongoing, prospective, populationbased study which started in 2002. This study is aimed at identifying environmental, genetic and biochemical factors associated with the development and progression of OA. Subjects between the ages of 50 and 80 years were randomly selected from the electoral roll in Southern Tasmania (population $229,000)$, with an equal number of men and women. The overall response rate was 57\%. Details on the radiographic and pain assessment have been previously described by Saunders et al. (2012). Briefly, a standing anteroposterior semiflexed view of the right knee with $15^{\circ}$ of fixed knee flexion was performed at baseline in all subjects. Western Ontario McMaster OA Index (WOMAC) pain questionnaire scores representing the last 30 days were used to classify symptomatic OA. Each knee pain item was summed to create a total pain (0-45) score. Prevalent knee pain was defined as a total score of 5 or above, corresponding to $<91$ on a $0-100$ scale $=$ worst to $100=$ no pain). Controls were individuals with no knee OA and no hip OA.

\subsubsection{Clearwater OA study (COS)}

This study is an ongoing community-based cohort study designed to identify risk factors for the development and progression of OA [previously described by Wilder et al. (2002)]. The COS was approved by the community-based Institutional Review Board of the Arthritis Research Institute of America, an uncompensated, nonemployee board that has representation from the medical disciplines. Study participants of either gender aged 40 years and older, with or without OA, have been included. Subjects completed a questionnaire detailing among other things demographics, and a module describing joint symptoms. Weight-bearing anteroposterior radiographs of both knees were taken at the first and all subsequent examinations and graded using an atlas (5). For this study, 175 individuals with a $\mathrm{K} / \mathrm{L} \geq 2$ at the first or second visit were included and compared for their painful knee status.

\subsection{Genotyping}

For all cohort study participants, genomic DNA was extracted from peripheral blood leucocytes using standard protocols. Genotyping was carried out by LGC genomics Ltd, Hertfordshire UK. SNPs were genotyped using the KASPar chemistry, which is a competitive allele-specific PCR SNP genotyping system using FRET quencher cassette oligos. Genotyping accuracy, as determined from the genotype concordance between duplicate samples was 99.6\%. Six SNPs in the SP receptor (TACRl) gene were genotyped in the GOAL participants rs4853119, rs1861457, rs10168354, rs3755456 and rs3771835 and rs 11688000 . Having found that only rs1 1688000 was nominally associated with pain in OA in this discovery cohort, this SNP was subsequently genotyped in the four replication cohorts. All variants were in Hardy-Weinberg Equilibrium (Tables 1 and 2 ) in the discovery and replication cohorts.

\subsection{Statistical analysis}

Logistic regression analysis was used to test genotype data for an association with: (1) symptomatic OA

Table 2 The results of logistic regression analysis showing the association of each of the six TACR1 SNPs with three measures of symptomatic versus asymptomatic osteoarthritis (OA). All analyses are adjusted for age, sex and BMI.

\begin{tabular}{|c|c|c|c|c|c|c|c|c|}
\hline SNP ID & $\mathrm{BP}$ & MAF & $\begin{array}{l}\text { Effect allele/ } \\
\text { No effect }\end{array}$ & $\begin{array}{l}\text { HWE } \\
p \text {-value }\end{array}$ & $\begin{array}{l}\text { Gene } \\
\text { location }\end{array}$ & $\begin{array}{l}\text { Symptomatic OA } \\
\text { versus controls } \\
\text { OR (95\%) }\end{array}$ & $\begin{array}{l}\text { Symptomatic OA } \\
\text { versus asymptomatic } \\
\text { OA ORi }(95 \%)\end{array}$ & $\begin{array}{l}\text { Controls versus } \\
\text { asymptomatic OA } \\
\text { OR (95\%) }\end{array}$ \\
\hline rs4853119 & 75416296 & 0.745 & $\mathrm{~T} / \mathrm{C}$ & 0.75 & Intron & 0.95 (0.80-1.13) & $1.05(0.88-1.26)$ & $0.93(0.75-1.16)$ \\
\hline rs1861457 & 75323267 & 0.330 & $\mathrm{~T} / \mathrm{C}$ & 0.79 & Intron & 0.89 (0.76-1.04) & $0.98(0.82-1.17)$ & $0.91(0.74-1.11)$ \\
\hline rs10168354 & 75382710 & 0.572 & $\mathrm{~T} / \mathrm{C}$ & 0.59 & Intron & $1.12(0.96-1.30)$ & $0.95(0.80-1.12)$ & $1.10(0.90-1.34)$ \\
\hline rs3755456 & 75287819 & 0.855 & $\mathrm{~T} / \mathrm{C}$ & 0.51 & Intron & $0.89(0.72-1.11)$ & $1.20(0.96-1.51)$ & 0.77 (0.59-1.00) \\
\hline rs3771835 & 75374043 & 0.453 & $\mathrm{~T} / \mathrm{C}$ & 0.36 & Intron & 0.92 (0.79-1.07) & $1.04(0.88-1.23)$ & $0.89(0.73-1.08)$ \\
\hline rs11688000 & 75293157 & 0.368 & $\mathrm{G} / \mathrm{A}$ & 0.49 & Intron & $1.04(0.89-1.22)$ & $0.84(0.70-1.00)^{*}$ & $1.19(0.97-1.46)$ \\
\hline
\end{tabular}

HWE, Hardy-Weinberg equilibrium.

*Bolded text and asterisk indicate $p<0.05$. 
versus controls; (2) asymptomatic OA versus controls and (3) symptomatic OA versus asymptomatic OA.

All analyses were run unadjusted and then adjusted for: (1) age, sex and BMI and, for data used in fixed effects meta-analysis using results from logistic regression analysis in each of the five groups; and (2) age, sex, BMI and maximum knee K/L grade. Maximum knee K/L grade was the maximum $\mathrm{K} / \mathrm{L}$ grade for either right or left knee. In sensitivity analysis using the GOAL cohort, logistic regression analyses were also adjusted for depression status, alongside age, sex, BMI and maximum K/L grade. The statistical package $\mathrm{R}$ (The R Foundation, version 3.0.2) was used to.... Any further adjustments are indicated in the results tables where applicable.

The 'meta' package for $\mathrm{R}$ was used to run a metaanalysis to test if any significant findings from the discovery analysis replicated in the other groups and give an overall effect.

These six SNPs represent $52.5 \%$ of the variation in the TACRl gene with $r^{2} \geq 0.6$ and MAF $5-50 \%$ (https://snpinfo.niehs.nih.gov/snpinfo/snptag.htm).

\section{Results}

Descriptive statistics of the study cohorts are shown in Table 1. Participants with knee pain generally had higher BMI, and were more likely to display $\mathrm{KL} \geq 3$ than those with radiographic OA without knee pain, but groups overall had similar ages and sex distributions.

It should be noted that KL grades were higher in the GOAL study, likely reflecting differences in the natures of the populations being sampled.

A nominally significant association was seen between rsl 1688000 genotype and symptomatic versus asymptomatic OA in the GOAL group in both the unadjusted analysis: $\mathrm{OR}=0.84 \quad 95 \% \quad 0.71-0.99$, and after adjusting for age, sex and BMI (Table 2).

No significant associations were seen for any of these SNPs between symptomatic OA versus controls, or asymptomatic OA versus controls (Table 2).

The association of rsl1688000 with symptomatic versus asymptomatic OA achieved $p<0.004$ in all replication cohorts combined. The direction of the genetic effect was the same in all cohorts with the G (minor) allele being associated with lower risk of symptomatic knee OA.

A fixed effects meta-analysis using results from the unadjusted logistic regression analysis in each of the five groups gave a final effect of: $\mathrm{OR}=0.80$ $95 \% \quad 0.70-0.91, \quad p=8.66 \times 10^{-4}$ (Fig. 1A). Using the results from the fully adjusted logistic regression
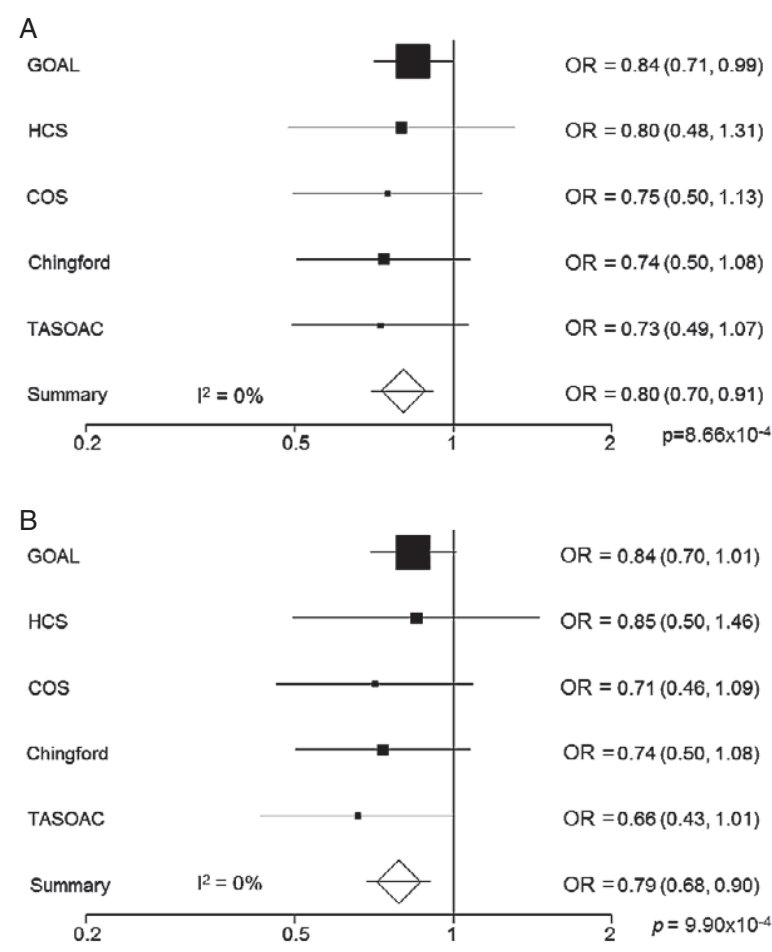

Figure 1 Forest plot showing the results of a fixed effects meta-analysis of the discovery group and the four replication groups used in the analysis of rs11688000 $\mathrm{G}$ allele in the TACR1 gene and its association with symptomatic osteoarthritis (OA) versus asymptomatic $O A(A)$ and after adjustment for age, sex, BMI and $\mathrm{K} / \mathrm{L}$ grade $(\mathrm{B})$.

analysis (adjusted for age, sex, BMI and maximum $\mathrm{KL}$ grade) gave a result of: $\mathrm{OR}=0.7995 \% 0.68$ $0.90, p=9.90 \times 10^{-4}$ (Fig. 1B). There was no significant heterogeneity between the five groups studied $\left(I^{2}=0 \%\right)$. After adjusting for multiple testing (six SNPs by three phenotypes), the necessary Bonferroni corrected $p$-value remained significant at 0.0027 .

Finally, we tested whether the association between TACRI and OA pain might be confounded by depression. Depression status was not available for the replication cohorts, but in the discovery cohort the odds ratio for SNP between people with radiographic OA with or without pain in the GOAL cohort following adjustment for age, sex, BMI, KL grade and depression was OR $=0.8495 \%$ CI 0.70 1.00 , essentially unchanged from the OR adjusted for age, sex, BMI and KL grade alone (Table 2).

\section{Discussion and conclusions}

This study found a genetic effect on the risk of symptomatic OA versus asymptomatic OA given by the rsll688000 SNP in the TACRl gene. To our 
knowledge, this is the first study to show an effect of variation in the TACRl gene on chronic pain.

We found no significant associations between symptomatic OA cases and controls or between asymptomatic $\mathrm{OA}$ cases and controls. A potential explanation for this is that the controls were selected based on X-rays and not on their knee pain status, and thus may include individuals with other forms of pain.

This study extends previously published work on the relevance of SP and its receptor in OA and OA pain (Marshall et al., 1990; Lindh et al., 1997; Zubrzycka and Janecka, 2000; Im et al., 2008) by showing significant effects of variants in the SP receptor gene on the risk of painful (symptomatic) OA. The results of this study support the involvement of TACRI gene in OA pain, and extend results from previous candidate gene studies on differences in pain perception and sensitivity. Variants in the TRPVI (rs8065080), COMT (rs4680), SCN9A (rs6746030) and PACE4 (rs900414) genes have been previously implicated in the risk of symptomatic versus asymptomatic OA (reviewed in Warner and Valdes, 2016), in that individuals with a particular allele at variants in these genes were more or less likely to report symptomatic OA versus asymptomatic OA, highlighting the role of genetics in the risk of clinical OA (Warner and Valdes, 2016). A variant in the TACRl gene has also been associated with responses to nociceptive stimuli in experimental pain in people without arthritis (Storm et al., 2013) indicating that this gene might contribute to variations in pain processing between individuals (Storm et al., 2013). Our data lead us to suggest that variations in TACR1 might partially explain differences in pain experience amongst people with radiographic knee OA. The rsl1688000 SNP A allele that was associated with increased risk of pain in our study, has also identified as being suggestively associated with alcohol dependence (AD; $n=326$; Blaine et al., 2013) further suggesting possible contributions to processes within the central nervous system. Given the known role of the substance P receptor in modulating dopaminergic pathways (Rupniak and Jackson, 1994; Renoldi and Invernizzi, 2006) and the association of the same variant found by us also with alcohol dependence, it is possible that the association seen between this TACRl variant and pain may be related to differences in dopamine modulation in the central nervous system.

This SNP is intergenic (noncoding) and its function is not known. However, intergenic SNPs can potentially influence transcription and therefore affect gene function. Functional work on this variant is required to follow-up these findings and put them into a biological context.

It should be noted also that both the associations we report with symptomatic OA and those previously reported for the TACR1 gene do not achieve genome-wide significance $(p<5 \times 10[-8])$ and therefore variants in this gene do not appear to have sufficiently large effects in depression and PTSD (Lewis et al., 2010; Logue et al., 2013). On the other hand, very little is known about the molecular determinants of interindividual differences to pain in $\mathrm{OA}$ and the association reported here raises the possibility that modulating TACR I activity pharmacologically could be used as a therapy for OA pain. An early randomized controlled trial failed to demonstrate analgesic efficacy for the $\mathrm{NK}_{1}$ receptor antagonist lanepitant in OA, but investigators argued that this was possibly due to poor central nervous system penetration of the compound and the heterogeneity seen in groups of people with OA (Goldstein et al., 2000). Despite the involvement of SP and its receptor in numerous physiological processes, there is at present an incomplete understanding of the therapeutic potential of $\mathrm{NK}_{1}$ receptor antagonists (Brain and Cox, 2006).

TACR1 is widely expressed in the body, including in both the central and peripheral nervous system (Almeida et al., 2004; Pinto et al., 2004), suggesting that further trials are needed to investigate how central and peripheral $\mathrm{NK}_{1}$ receptors can be better targeted. For example, peripheral and central pain are both seen in people with $\mathrm{OA}$ and these different pathologies require different treatment and research approaches. Studies have shown that SP is an important component of the inflammatory response at peripheral sites, in conjunction with other factors (Pantaleo et al., 2010).

One aspect that must be considered regarding the potential efficacy of $\mathrm{NK}_{1}$ receptor antagonists as analgesics is the age-dependent effect of SP in pain. There is evidence from animal models showing that NK1 receptor modifies the development of symptoms and that substance $\mathrm{P}$ modifies the sensitization of joint receptors receptors in an age-dependent manner. (Cruce et al., 2001; McDougall and Schuelert, 2007). Although, our results are adjusted for age it is possible that any compounds targeting substance $\mathrm{P}$ for OA pain could have different efficiacies depending on age and this may explain some of the lack of efficacy seen in previous studies.

More recently, $\mathrm{NK}_{1}$ receptor antagonists have been shown to be efficacious or have strong potential for 
use in various neurobehavioral indications, such as depression, stress, anxiety, alcoholism and post-traumatic stress disorder (summarized in Hallberg, 2015). For example, some $\mathrm{NK}_{1}$ receptor antagonists (such as orvepitant) display good penetration of the CNS, and can improve symptoms of depression and improve sleep quality (Ratti et al., 2013). Use of LY686017, another $\mathrm{NK}_{1}$ receptor antagonist, was associated with lower alcohol consumption suppressed alcohol cravings in recovering alcoholics (George et al., 2008). Given that the same variant associated with higher risk of alcoholism in the TACR I gene is also associated with higher risk of OA pain, this suggests the possibility that the same antagonists may have a positive effect on OA pain. It remains possible that $\mathrm{NK}_{1}$ receptors are important in OA pain only for a subgroup of the population, for example those with the associated TACRl variants, and further research should also determine whether TACRl variants predict analgesic response to $\mathrm{NK}_{1}$ antagonists in knee OA.

We note several study limitations. In this study, we covered only $52.5 \%$ of the variation within the TACRl gene; hence, we may have missed stronger associations at other variants within this gene. Additionally, this variant has no currently identified functional correlate, so the mechanism of its effect in alcohol dependence and pain in OA is unknown. Importantly, the SNPs identified by us, as other variants associated to psychiatric traits in this gene, do not derive from genome-wide association studies achieving the critical $p$-value of $5 \times 10[-8]$. Such a stringent level is achieved only in the presence of very strong genetic effects and or very large sample sizes which were not available in our study.

Other potential limitations include the radiographic assessment of knee OA which was limited just to the tibio-femoral compartments without assessment of the patello-femoral compartment which is commonly affected by OA and may also associate with pain and the fact that the study included only Caucasian participants, as is common in genetic studies, and therefore the findings might not be applicable to groups from other ethnic backgrounds.

Depression was a potential confounder although in the discovery cohort, where available data permitted classification for depression, the association of rs11688000 and symptomatic versus asymptomatic OA was unaffected by for depression.

The $\mathrm{NK}_{1}$ receptor encoded by TACRl is a potential therapeutic target for which small molecule antagonists have already been developed for use in man.
Further research is needed to determine the mechanisms by which $\mathrm{NK}_{1}$ receptor variants might influence OA pain, and their relative importance compared to other genetic or environmental factors for individuals with knee or other forms of arthritis. For example, there are currently no published genome-wide studies comparing symptomatic versus asymptomatic OA. The precise mechanisms underlying the asymptomatic presentation of $\mathrm{OA}$ require further study.

In conclusion, the results of this study support a role of SP and its receptor in pain experienced by some people with $\mathrm{OA}$. $\mathrm{NK}_{1}$ receptor antagonists might have potential for the treatment of pain, at least in subgroups of people with OA who carry the rs 11688000 allele studied here.

\section{Acknowledgements}

The authors gratefully acknowledge the contributions of Sally Doherty and Maggie Wheeler to patient assessments at baseline, data collection and entry. We would also like to thank the GOAL Study team. We would like to thank all the participants of the Chingford Women Study, Maxine Daniels and Alison Turner for their time and dedication and Arthritis Research UK for their funding support to the study and the Oxford NIHR Musculoskeletal Biomedical Research Unit for funding contributions.

\section{Author contributions}

All authors have read, provided critical feedback on intellectual content and approved the final manuscript.

\section{References}

Aihie Sayer, A., Syddall, H.E., Dennison, E.M., Gilbody, H.J., Duggleby, S.L., Cooper, C., Barker, D.J. and Phillips, D.I. (2004). Birth weight, weight at $1 \mathrm{y}$ of age, and body composition in older men: Findings from the Hertfordshire Cohort Study. Am J Clin Nutr 80,199-203.

Almeida, T.A., Rojo, J., Nieto, P.M., Pinto, F.M., Hernandez, M., Martín, J.D., Candenas, M.L. (2004). Tachykinins and tachykinin receptors: Structure and activity relationships. Curr Med Chem 11, 2045-2081.

Blaine, S., Claus, E., Harlaar, N., Hutchison, K. (2013). TACRl genotypes predict fMRI response to alcohol cues and level of alcohol dependence. Alcohol Clin Exp Res 37, E125-E130.

Brain, S.D., Cox, H.M. (2006). Neuropeptides and their receptors: Innovative science providing novel therapeutic targets. $\mathrm{Br} J$ Pharmacol 147, S202-S211.

Cruce, W.L., Lovell, J.A., Crisp, T., Stuesse, S.L. (2001). Effect of aging on the substance $\mathrm{P}$ receptor, NK-1, in the spinal cord of rats with peripheral nerve injury. Somatosens Mot Res 18, 66-75.

George, D.T., Gilman, J., Hersh, J., Thorsell, A., Herion, D. et al. (2008). Neurokinin 1 receptor antagonism as a possible therapy for alcoholism. Science 319, 1536-1539.

Goldstein, D.J., Wang, O., Todd, L.E., Gitter, B.D., De Brota, D.J., Iyengar, S. (2000). Study of the analgesic effect of lanepitant in patients with osteoarthritis pain. Clin Pharmacol Ther 67, 419-426. 
Hallberg, M. (2015). Neuropeptides: Metabolism to bioactive fragments and the pharmacology of their receptors. Med Res Rev 35, 464-519.

Hart, D.J., Spector, T.D. (1993). Cigarette smoking and risk of osteoarthritis in women in the general population: The Chingford study. Ann Rheum Dis 52, 93-96.

Hunter, D.J., Guermazi, A., Roemer, F., Zhang, Y., Neogi, T. (2013). Structural correlates of pain in joints with osteoarthritis. Osteoarthr Cartil 21, 1170-1178.

Im, H.J., Li, X., Muddasani, P., Kim, G.H., Davis, F. et al. (2008). Basic fibroblast growth factor accelerates matrix degradation via a neuroendocrine pathway in human adult articular chondrocytes. $J$ Cell Physiol 215, 452-463.

Klepstad, P., Fladvad, T., Skorpen, F., Bjordal, K., Caraceni, A., Dale, O., Davies, A., Kloke, M., Lundström, S., Maltoni, M., Radbruch, L., Sabatowski, R., Sigurdardottir, V., Strasser, F., Fayers, P.M., Kaasa, S. (2011). Influence from genetic variability on opioid use for cancer pain: A European genetic association study of 2294 cancer pain patients. Pain 152, 1139-1145.

Lewis, C.M., Ng, M.Y., Butler, A.W., Cohen-Woods, S., Uher, R. et al. (2010). Genome-wide association study of major recurrent depression in the U.K. population. Am J Psychiatry 167, 949-957.

Lindh, C., Liu, Z., Lyrenas, S., Ordeberg, G., Nyberg, F. (1997). Elevated cerebrospinal fluid substance p-like immunoreactivity in patients with painful osteoarthritis, but not in patients with Rhizopatic pain from a herniated lumbar disc. Scand J Rheumatol 26, 468-472.

Logue, M.W., Baldwin, C., Guffanti, G., Melista, E., Wolf, E.J. et al. (2013). A genome-wide association study of post-traumatic stress disorder identifies the retinoid-related orphan receptor alpha (RORA) gene as a significant risk locus. Mol Psychiatry 18, 937-942.

de Luca, K., Parkinson, L., Downie, A., Blyth, F., Byles, J. (2016). Three subgroups of pain profiles identified in 227 women with arthritis: A latent class analysis. Clin Rheumatol, 1-10. DOI: 10.1007/ s10067-016-3343-5.

Marshall, K.W., Chiu, B., Inman, R.D. (1990). Substance P and arthritis: Analysis of plasma and synovial fluid levels. Arthritis Rheum 33, 87-90.

McDougall, J.J., Schuelert, N. (2007). Age alters the ability of substance P to sensitize joint nociceptors in Guinea pigs. J Mol Neurosci 31, 289296.

Pantaleo, N., Chadwick, W., Park, S.S., Wang, L., Zhou, Y., Martin, B., Maudsley, S. (2010). The mammalian tachykinin ligand-receptor system: An emerging target for central neurological disorders. CNS Neurol Disord Drug Targets 9, 627-635.
Pinto, F.M., Almeida, T.A., Hernandez, M., Devillier, P., Advenier, C., Candenas, M.L. (2004). mRNA expression of tachykinins and tachykinin receptors in different human tissues. Eur J Pharmacol 494, 233-239.

Ratti, E., Bettica, P., Alexander, R., Archer, G., Carpenter, D. et al. (2013). Full central neurokinin-1 receptor blockade is required for efficacy in depression: Evidence from orvepitant clinical studies. $J$ Psychopharmacol 27, 424-434.

Renoldi, G., Invernizzi, R.W. (2006). Blockade of tachykinin NK1 receptors attenuates stress-induced rise of extracellular noradrenaline and dopamine in the rat and gerbil medial prefrontal cortex. $J$ Neurosci Res 84, 961-968.

Rupniak, N.M., Jackson, A. (1994). Non-specific inhibition of dopamine receptor agonist-induced behaviour by the tachykinin NK1 receptor antagonist CP-99,994 in guinea-pigs. Eur J Pharmacol 262, 171-175.

Saunders, J., Ding, C., Cicuttini, F., Jones, G. (2012). Radiographic osteoarthritis and pain are independent predictors of knee cartilage loss: A prospective study. Intern Med J 42, 274-280.

Sharp, S.I., McQuillin, A., Marks, M., Hunt, S.P., Stanford, S.C., Lydall, G.J., Morgan, M.Y., Asherson, P., Curtis, D., Gurling, H.M.D. (2014). Genetic association of the tachykinin receptor 1 TACRl gene in bipolar disorder, attention deficit hyperactivity disorder, and the alcohol dependence syndrome. Am J Med Genet B Neuropsychiatr Genet $165,373-380$.

Storm, H., Støen, R., Klepstad, P., Skorpen, F., Qvigstad, E., Ræeder, J. (2013). Nociceptive stimuli responses at different levels of general anaesthesia and genetic variability. Acta Anaesthesiol Scand 57, 89-99.

Valdes, A.M., De Wilde, G., Doherty, S.A., Lories, R.J., Vaughn, F.L. et al. (2011). The Ile585Val TRPV1 variant is involved in risk of painful knee osteoarthritis. Ann Rheum Dis 70, 1556-1561.

Warner, S.C., Valdes, A.M. (2016). The genetics of osteoarthritis: A review. J Funct Morphol Kinesiol 1, 140.

Wilder, F.V., Hall, B.J., Barrett, J.P. Jr, Lemrow, N.B. (2002). History of acute knee injury and osteoarthritis of the knee: A prospective epidemiological assessment the clearwater osteoarthritis study. Osteoarthr Cartil 10, 611-616.

Yan, T.C., Hunt, S.P., Stanford, S.C. (2009). Behavioural and neurochemical abnormalities in mice lacking functional tachykinin-1 (NK1) receptors: A model of attention deficit hyperactivity disorder. Neuropharmacology 57, 627-635.

Zubrzycka, M., Janecka, A. (2000). Substance P: Transmitter of nociception (Minireview). Endocr Regul 34, 195-201. 